\title{
The Significance of Community for Greek Australians Living in Diaspora
}

\author{
By Maria-Irini Avgoulas ${ }^{*} \&$ Rebecca Fanany ${ }^{ \pm}$
}

\begin{abstract}
This paper will elucidate the importance of community and the significance of this for Greek Australians living in diaspora. It is based on a series of qualitative research projects undertaken by very experienced researchers, exemplifying both an emic and etic position relative to this diaspora population. Through the application of Narrative Ethnography, the lived experience of this population across the generations will be discussed. This experience will be further highlighted through the presentation of a profile of the Greek community in Melbourne illustrating the lived experience and community identity of its members. This will exemplify perceptions of what 'community', 'community connections' and 'social connectedness' mean to Greek Australians and allow the influence on their emotional health and wellbeing to be examined. This lived experience aims to show how a perception of Greekness influences healthrelated behavior, especially diet and nutrition, and creates a sense of wellbeing among members of the community. The findings of this study have wider implications for the understanding of the Greek experience in Australia and show the importance of community and the significance of cultural practices to overall psychological wellbeing. They also contribute to a wider knowledge base and will inform interventions intended to address well-being and health for members of the Greek population. This might be of assistance in policy making and meeting the health needs of multicultural communities more broadly.
\end{abstract}

Keywords: Community, Greek Australian, Diaspora, Qualitative, Narrative Ethnography

\section{Introduction and Background}

Australia is committed to providing culturally appropriate health care and services to its population, and this principle is incorporated into the service contract of Medicare, the national healthcare system (Department of Human Services, 2012). Achieving this aim requires an in-depth understanding of the cultural needs of all Australian ethnic groups to meet and ehance health and wellbeing for all. This includes the role and influence of the language and cultural background of various communities and how these factors may affect wellbeing and attitudes towards health care and healthcare professionals. One of Australia's major cultural communities is made up of individuals of Greek background. The Greek community has been in existence in Australia since 1827, with the vast majority of its members arriving in the period following World War II and the

\footnotetext{
*Associate Lecturer, La Trobe University, Australia.

${ }^{ \pm}$Associate Professor, Central Queensland University, Australia.
} 
Greek civil war aboard the many ships that left from Piraeus, Athens (Avgoulas and Fanany 2015). Despite their long residence as a community in Australia and high level of integration into the Australian mainstream, people of Greek background have maintained a distinct cultural perspective as well as linguistic patterns and daily practices that reflect their culture of origin. This has persisted among members of the younger generations who were born in Australia and have become English speakers and Australians in terms of overall lifestyle.

The research reported here (undertaken by Avgoulas, M-I who is one of the authors of this paper), which included both male and female participants of three generations, was undertaken in Melbourne, which has one of Australia's largest populations of people of Greek background. The Greek community is dynamic and maintains many social and cultural organizations and institutions that reflect the national and cultural heritage of community members. It's important to note early on that this paper is based three qualitative studies. These are:

1. A 2011 qualitative study entitled 'Cultural Understanding of Health and Adjustment to Cardiovascular Disease among the Greek elderly', which involved 13 participants (five male and eight female) aged over 60 over a one-month period. This research specifically examined the health beliefs of elderly Greek Australians and the way they understand health and disease;

2. A 2012 qualitative study that was part of a $\mathrm{PhD}$ research project that was entitled 'Health Beliefs and Practices in Three Generations of Greek Australian Women in Melbourne'. This research investigated the health beliefs and practices in three generations of Greek Australian women in Melbourne. A Total of 48 women took part in this study, representing immigrant, first and second generation members of participating families;

3. A 2016 qualitative study investigating 'Greek dancing as an aspect of cultural identity and wellbeing'. Nineteen male and female participants aged over 18 from Manasis School of Greek Dance and Culture in Melbourne, Australia, took part in this study that focused on the reasons these individual sparticipated in Greek dancing while living in Diaspora.

The first author of this paper (Avgoulas) is a member of this community and occupies an insider position in relation to language and cultural background. This was an advantage in this study as many older individuals are most comfortable using Greek and cannot fully express their ideas and perceptions in English. In addition, an understanding of the cultural assumptions was extremely important in developing a comprehensive picture of the role of food and diet in contributing to overall well-being as understood by the participants.

\section{Narrative Ethnography}

The literature describes ethnography as an active relationship between the researcher and the population(s) being studied (Boyle 1994, Marcus and Fisher 
1986). In addition, it has been seen as a research activity that is located within the community of interest (Moeran 2007). Goodall (2004) sees ethnography as a form of storytelling where the subject matter is real life. Understood in this way, ethnography shares characteristics with oral history, in that both disciplines focus on the perceptions of the individuals concerned, but where oral history is concerned primarily with documenting the meaning of events internal to the community of study, ethnography strives to offer a comparison with external contexts that may be similar or may contrast with that of the community of interest (see, for example, Leavy 2011, for discussion of this).

The need to understand the specific culturally-based perspective of various communities is well accepted, especially in fields like health, where such perspectives can affect a range of outcomes that have real implications to the people involved. An ethnographic approach is especially suited to elucidating these culturally-determined views. Nonetheless, while traditionally focused on local contexts and the experiences of individuals who are part of small, distinct groups, it is increasingly recognized that ethnography can and should expand beyond place-centered studies (Merry 2000). In an increasingly globalized world, individuals and the local communities of which they are a part, are affected by events and ideas that originate elsewhere. This is very much the case in the Greek community in Melbourne, whose members view themselves as connected to Greek people in Greece as well as in other diaspora communities and whose perceptions of themselves and their culture draw on the memories and interpretations of the original immigrant commnunities but are also supplemented by new understandings that derive from a more global concept of Greekness available through the internet and social media that is growing in importance, even as the community shifts more toward English and away from Greek as a the mediating language of culture and social experience. The way in which the individuals who took part in this study understand their own experience, then, is very different from the kinds of understanding that might have been more traditionally expected from ethnographic study. This underscores the importance of eliciting the same kind of deeper, more nuanced responses from study participants in order to fully depict their experience in a way that can be applied to the relevant contexts, including health and wellbeing.

\section{The Greeks of Melbourne}

The Greek community in Melbourne, Australia, is large and dynamic. It has been in existence for more than 100 years since the first migrants from Greece began to arrive in Australia. However, it increased greatly in size and strength after the second World War, when thousands of new migrants hoping for a better life in a new country left Greece to settle in "the lucky country" (Tamis 2005). Today, the original migrants are the parents and grandparents (and even great grandparents) of a community of Greek Australians who are highly integrated into the mainstream of Australian society (Clyne 2011). While these older Greek individuals often do not speak English well and try to maintain what they see as a 
Greek lifestyle, the first Australian born generation is often bilingual and occupies a position that bridges the Greek orientation of their parents and the lifestyle of the Australian mainstream. The members of the second Australian born generation, many of whom are now young adults, are native speakers of English; many have only rudimentary Greek and are more like their peers from other ethnic backgrounds in terms of lifestyle than they are similar to their grandparents. This can be seen as a result of the adaptability of the community but also as a reaction to the difficulties of the migration experience that suggested to many members of the community that mastery of the mainstream language and culture of Australia was necessary for successful integration into a new cultural milieu.

Nonetheless, the Greek community of Melbourne has established and maintained several institutions intended to transmit Greek culture to younger people. These include Greek language schools, social and sporting organizations, and Greek Orthodox churches, which continue to be important community institutions despite a general trend away from organized religion in Australia (Bouma, 2006). The elements that characterize membership in the Greek community not surprisingly center on religious perspective and participation as well as in food practices and linguistic behaviour that includes use of Greek terms for family members, events and practices of cultural importance, names of food items, and so forth, even among individuals who do not otherwise speak Greek.

Their Greek Orthodox background often gives members of the Melbourne Greek community a strong and persistent worldview that centres on belief in God and His power and benevolence. This view was shared by members of all genrations, genders and ages in all three studies. - One $2^{\text {nd }}$ generation participant from study 2 expressed this view as follows: "When someone has cancer, it could be in their genes but it could have started ages ago. God may have given it to a certain person and put it in their genes and decides when it will appear." This translates into a view of pre-determined fate, especially among older people, that is dependent on God's will. This view is often expressed in terms of a two-fold perspective centering on health and well-being. This conceptualization suggests that the individual has a responsibility to improve his or her health and overall wellbeing through reasonable efforts that are within his or her capability to carry out. This religious perspective also leads to a strong focus on emotional health and wellbeing among all generations of the community. Individuals of all ages recognize the negative impacts of stress and acknowledge a role for religious faith in ameliorating these detrimental effects. Many rely on prayer and religious rituals as a source of strength and use them to cope with adversity, with participation in culturally important events, such as fasting before Easter, serving a source of resilience as well as a marker of cultural identity and community belonging. While even the older members of the community are aware of the health impacts of smoking and diet, for example, and the younger members tend to have to same views on health as the population in general, the social and emotional value of religion is notable across the community, and religious participation is a characteristic feature of the Greek community that sets it apart from other ethnic and cultural groups in Australia (see Watson 2009). 
Food is another significant marker of cultural identity and one that members of the Greek community are proud of. The role and importance of food and food practices come from the original migrants. Specific food preferences and eating habits associated with Greece are desirable and serve as clear markers of cultural identity. This extends, not just to a preference for specific dishes or methods of preparation, but also to the maintenance of home gardens. The Australian climate is well-suited to many of the plants that grow in Greece that the original migrants were familiar with. For this reason, it was possible to recreate an aspect of the agricultural life that characterized the background of most of these early arrivals and represents a significant part of their memory culture of agricultural life in Greece. The younger generations, even when they do not have time or an inclination to engage in serious gardening, tend to value growing one's own fruit and vegetables, and many younger people aspire to have a garden like that of their grandparents someday. In addition to the obvious health benefits of gardening as a source of light exercise and psychological wellbeing, water and soil are seen by many Greek Australians as a link to their traditional homeland and a source of strength and perseverance. This has been especially significant in sustaining them emotionally, especially in the harder times of the past. In addition, the presence of a home garden whose produce is familiar and fits with traditional food culture has served to sustain the food practices of the community over time. While the community's diet has, of course, changed in Australia along with its integration into the mainstream culture as well as its rising economic status that allows for greater variety, many Greek Australians believe in the ancient principle of $\pi \alpha v$

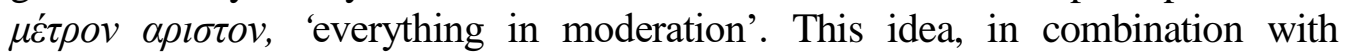
continuing adherence to a largely Mediterranean diet, may account for some health advantages enjoyed by the Australian Greek community in comparison with the population as a whole as well as with other ethnic and cultural groups (see, for example, Hodge et al. 2011).

Food is an integral aspect of heritage and responsibility to family, identity and cultural practices that must be shared and maintained, despite the community's situation in diaspora. Members of all generations of the Greek community associate their food choices with what they or their elders knew in Greece, their culture and Hellenic heritage. Many feel an obvious pride at being different in this way from the Australian mainstream and believe their way of eating to be healthier and more beneficial than what they consider to be outside of their cultural purview. This view predominates, even among younger people, who, in fact, tend to be quite similar to their peers in terms of diet. Food items seen as healthier and better overall include white bean (cannellini bean) soup, lentils, wild greens and fish, which members of the community associate with experience in Greece. Older individuals are often disappointed and concerned that their children and grandchildren do not like Greek dishes as much as they hope and, as a result, do not cook these kinds of food. They tend to see a more Australian diet as less beneficial for health in addition to being a poor cultural fit. Younger members of the community perceive themselves differently, however, and often express their attachment to the food practices of their heritage culture. This is often expressed as a dependence on specific items, such as olive oil, that are culturally significant and 
represent staples in Greek cooking. Like their elders, these younger Greek Australians often see 'Greek' food as more nutritious and flavorful as well as emotionally significant. They also frequently share the view of their parents and grandparents that processed food should be avoided, that everything should be enjoyed in moderation, and it is best to eat the kinds of foods they were raised on, regardless of whether they practice various aspects of their heritage food culture themselves.

The practice of fasting before Easter is an important cultural and religious ritual in the Greek community in Melbourne. Members of the community tend to see this as something that is specifically Greek, despite the more general occurrence of abstinence during Lent among various Christian communities. While clearly a religious act, many Greek Australians believe there is a health benefit associated with giving up certain foods during this period, and younger people especially use the practice as a means to control diet and restrict their food intake. Interestingly, attitudes toward the necessity of fasting seem to be increasingly relaxed. For example, while universally seen as beneficial with in the Greek community, fasting by those who take regular medication is seen as negative. In this, the need to follow medical advice is viewed as taking precedence over religious requirements. Similarly, many members of the community believe that it is appropriate not to fast or to take a break from fasting when in the presence of friends or at a social gathering that involves people from other backgrounds, as the need to be socially appropriate and not stand out in this way is seen as more important than religious observance. This kind of flexibility is an example of the cultural perspective that has facilitated the integration of people of Greek background into Australian society, but, at the same time, the significance and perceived uniqueness of religious fasting cannot be overestimated. For many members of the community, this socioreligious practice is seen as an infallible mark of identity and community belonging.

Overall, members of the Greek community in Melbourne believe in the knowledge and abilities of the modern healthcare system and its practitioners. Greece has a long tradition of medical practice that can be traced back to Hippocrates in ancient times. As a result of this perhaps, the community has comparatively few traditional or home remedies that are in use. Older individuals often know about and have used such methods but generally believe them to be inferior to the medical knowledge possessed by trained practitioners. An exception to this is belief in the evil eye and the efficacy of traditional means to fight this negative influence. While it is mostly the older generation of migrants who are familiar with these traditional practices, younger people often believe in this kind of illness and the means to treat it. Nonetheless, members of the Greek community have few qualms about using the healthcare system and are generally open to health advice and treatment proposed by doctors, including that related to diet and nutrition. In fact, their religious perspective seems to support the use of medical care, as this is seen as obeying God's wishes for them by responding to illness by making an effort to seek appropriate help and accept treatment that is available. This, along with maintaining a healthy and culturally fitting diet and the belief that 
God will not challenge them beyond their ability to cope, makes for overall high resilience and emotional stability in the Greek community in Melbourne.

Despite great pride in their cultural heritage and Greek way of life, members of the Greek Australian community tend to be very private about their cultural practices. One participant from Study 3 explained: "Even though they [elders] are not dancing when they are audience well it provides them with joy, they are so proud, even when they see their grandchildren but it's the same thing when they see strangers - we are automatically connecting and bonding it could be a song, a dance, a memory - its our culture and where they grew up".This may be a result of the experiences of older members of the community at a time when discrimination against non-English speaking groups was strong in Australia, and they experienced difficulties finding work and adjusting to the Australian context when they first arrived (Tamis 2005). Family ties remain important as do linguistic bonds, even if the latter are manifested only in names of obvious Greek origin among many of the younger members of the community. Today links to their region of origin are fading in significance as most of the community was born in Australia (Avgoulas and Fanany 2015). Nonetheless, the community remains tightly knit, such that its characteristic diversities may not be immediately visible to outsiders who may overestimate the impact of cultural commonalities of the Australian mainstream on the perceptions and experience members of the Greek community.

\section{Discussion and Conlusion}

Despite the efforts at cultural maintenance and the heavy investment made by the original immigrant generation to create a feeling of Greekness in their Australian-born descendants, the Greek community appears to be "Australian" in many ways. This is especially the case among younger people who were born in Australia, and one of the ways in which this cultural shift is visible is in the food choices and eating patterns that are common in different age cohorts. Despite widespread agreement that a Greek diet is preferable and healthier, first and second generation Greek Australians eat more like other Australians of the same age than like the cultural pattern their elders wish they would preserve. Time is a major factor in this, with many individuals noting that Greek food requires a great deal of preparation and cooking time that is increasingly scarce. While many also feel that Greek food is healthier and overall better for one's health and wellbeing, as noted, cultural practices such as fasting are sometimes used for weight management, many individuals also believe that Greek food is very heavy, especially in the very hot Australian summers. Not surprisingly, there are many efforts to adapt Greek food or dishes to the demands of modern life, and food and cooking continue to be topics of interest in the social media created and used by members of the Greek diaspora, both in Australia and elsewhere in the world. There is no doubt that eating a Greek diet (or a diet that is Greek in essence) has been closely associated with cultural identity in Australia, but it is also the case that this identity is shifting because of the experience of younger people that is 
increasingly "Australian" in nature. One reason for this is that those born in Australia are English speakers and feel themselves to be part of the Australian mainstream, despite an additional identity of Greekness. While this second identity is typically very important to those involved, it exists largely as an emotional dimension, rather than a set of hehaviors that are easily observed.

Greekness can be difficult to see, especially among the younger generations. The brief profile of Greeks in Melbourne presented here illustrates some of the less visible aspects of this cultural identity and exemplifies the way in which food and diet fit into individuals' perceptions. This is the type of phenomenon that a narrative ethnographic approach can effectively address, as has been used in this case. In order to understand the dimensions of ethnic identity in this community, it is necessary to elucidate how individuals see themselves and the meanings they give to the events of their life, which may not appear distinctive to casual observation. In the case of the Greek community, researchers who occupy an insider position have an additional advantage. The historical experience of older family members seems to have created a feeling of caution toward outsiders interested in the Greek experience. In addition, insider knowledge of the way language is used, cultural practices, and the nature of the local Greek communities is helpful in interpreting the contributions of study participants and placing their experiences within the broader Australian context. Such local place-based knowledge is likely to become increasingly important as the presence of outside ideas and perceptions that often derive the online world continues to affect the direct experience of individuals' lives and their perception of their own identity.

In addition, as social and cultural diversity continue to increase, the importance of understanding the specific experiences and eprceptions of various cultural and ethnic communities is likely to grow. In order to provide relevant services, to achieve the best outcomes from health care, and to ensure high levels of satisfaction among users, specific cultural insight is needed by practitioners as well as policymakers and educators (NHMRC 2006). While the approach is generally accepted as a requirement of culturally appropriate practice, it can only be achieved if based on a thorough understanding of the relevant aspects of specific cultures that are part of the community of interest (see, for example, Young and Guo 2016, Henderson et al. 2018). This knowledge can most appropriately come from an interdisciplinary approach to public health and wellbeing that draws on the methods developed in other fields that are applied to specific questions relevant to the health and scial services context. Narrative ethnography is one of these, and there are others, that have the potential to expand our understanding of culture, its impact on identity, and the ways in which this affects the experience of health, illness, and wellbeing. 


\section{References}

Avgoulas MI, Fanany R (2015) The Greek diaspora of Melbourne Australia through the eyes of the second generation Greek Australian. Athens Journal of Social Sciences 2(2): 99-108.

Boyle J (1994) Styles of ethnography. In Morse J (ed) Critical Issues in Qualitative Research Methods. Thousand Oaks, CA: Sage Publications.

Bouma G (2006) Australian Soul. Melbourne: Cambridge University Press.

Clyne M (2011) Multilingualism, Multiculturalism and Integration. In Clyne, M and Jupp, J, (eds) Multiculturalism and Integration: A Harmonious Relationships, 53-72. ANU Press, Canberra.

Department of Human Services (2012) Our service Commitments, Australian Government, Canberra. https://bit.ly/3jLU37z.

Goodall HL Jr (2004) Commentary. Journal of Applied Communication Research 32(3): 185-194. doi: 10.1080/0090988042000240130.

Henderson S, Horne M, Hills R, Kendall E (2018) Cultural Competence in Healthcare in the Community: A Concept Analysis. Health and Social Care in the Community 26(4): 590-603.

Hodge AM, Engoish, DR, Itsiopoulos C, O'Dea K, Giles GG (2011) Does A Mediterranean Diet reduce the Risk Associated with Diabetes?: Evidence from the Melbourne Collaborative Cohort Study. Nutiriton, Metabloism and Cardiovascular Diseases 21(9): 733-739.

Leavy P (2011) Oral History. New York: Oxford UP.

Marcus G, Fischer M (1986) Anthropology as cultural critique: an experimental moment in the human sciences. Chicago: University of Chicago Press.

Merry SE (2000) Crossing Boundaries: Etyhnography in the $21^{\text {st }}$ centruey. PoLAR 23(2): $127-134$.

Moeran B (2007) From Participant Observation to Observant Participation: Anthropology, Fieldwork and Organizational Ethnography.

National Health and Medical Research Council (NHMRC) (2006) Cultural Competency in Health: A Guide for Policy, Partnerships and Participation. Canberra: Commonwealth of Australia.

Tamis AM (2005) The Greeks in Australia. Melbourne: Cambridge UP.

Watson S (2009) Performing Religion: Migrants, the Church and Belonging in Marrickville, Sydney. Culture and Religion: An Interdisciplinary Journal 10(3): 317338.

Young S, Guo KL (2016) The Necessity of Cultural Competence for Health Care Providers and in Nursing Practice. The Health Care Manager 35(2): 94-102. 
